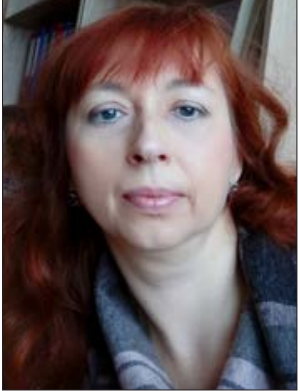

Natalia P. Savchenko,

Савченко Наталя Панасівна

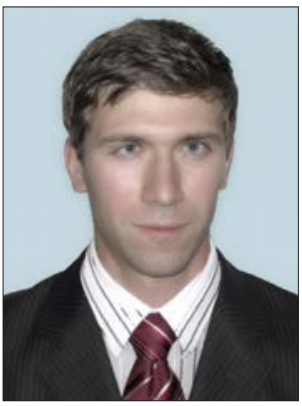

Andrii V. Tretiak, трет'як Андрій Валерійович

УДК 621.31

\title{
RESEARCH OF LOADING DIAGRAMS OF KINETIC ENERGY ACCUMULATORS WITH DIFFERENT CONTROL ALGORITHMS
}

\section{ДОСЛІДЖЕННЯ НАВАНТАЖУВАЛЬНИХ ДІАГРАМ КІНЕТИЧНИХ ЕНЕРГОНАКОПИЧУВАЧІВ ПРИ РІЗНИХ АЛГОРИТМАХ КЕРУВАННЯ}

\author{
DOI https:// doi.org/10.15589/smi2020.1(13).3
}

Natalia P. Savchenko

Савченко Наталя Панасівна, канд. тех. наук

natali a savchenko@ukr.net

ORCID: 0000-0001-7046-0633

Andrii V. Tretiak

Трет’як Андрій Валерійович, канд. тех. наук tretjak a.v@ukr.net

ORCID: 0000-0003-3971-3078

\section{Donbas National Academy of Civil Engineering and Architecture, Kramatorsk, Donetsk region \\ Донбаська національна академія будівнищтва і архітектури, м. Краматорськ, Донецька область}

Abstract. Prospects for the use of kinetic drives in the processes of transformation, distribution and conservation of electric power due to their environmental friendliness and durability. Despite the progressive development of technical and technological solutions for the constructive implementation of kinetic energy storage, the issues of improving the energy efficiency of their work are not considered sufficiently deeply, especially in connection with the performed functions in electrical networks. The article presents an experimental study of load diagrams of kinetic energy storage devices in single and group modes depending on different control algorithms and functions performed. Research Methods - An experimental simulation of "charge-storage-discharge" processes in kinetic storage devices on a developed prototype of a group of kinetic storage devices. As a result of the conducted researches it was found that a single use of the drive is expedient in the operating mode when the storage device is discharged by about $60 \%$ after which its charge goes. In this mode, we have the highest efficiency. With the group use of kinetic storage devices, the efficiency of parallel connection and simultaneous "charge-discharge" mode is achieved if necessary to quickly cover the peak load. With the alternate algorithm of the storage devices, the efficiency of the work is achieved with long-term load coverage. The conclusions made regarding the modes of operation of the storage devices in the system "drive-consumer" are fully confirmed by the received load diagrams. Kinetic drive load charts were also experimentally obtained while managing common parameters such as rotation speed engine generator, charge-discharge time, value of accumulated power and efficiency, which allowed us to draw conclusions about the optimality of their choice. The conducted researches have practical and scientific importance. From a scientific point of view, we have the results for further study of kinetic storage devices while optimizing the "driveconsumer" system. Practical importance is the application of the results obtained in the design of the system "drive-consumer" for the needs of power systems.

Key words: load diagram, kinetic energy storage (KES), flywheel, charge-discharge of the drive, control algorithm.

Анотація. Перспективи застосування кінетичних накопичувачів е процесах перетворення, розподілу та збереження електроенергії зумовлені їх екологічністю й довговічністю функціонування. Незважаючи на прогресивний розвиток технічних і технологічних рішень конструктивного виконання кінетичних накопичувачів енергії, питання підвищення енергоефективності їх роботи розглянуті недостатньо глибоко, особливо в прив'язці до виконуваних функцій в електричних мережах. У статті представлено експериментальне дослідження навантажувальних діаграм кінетичних накопичувачів енергії при одиночному та груповому режимах роботи залежно від різних алгоритмів управління й виконуваних функцій. Методи дослідження - експериментальна імітація процесів «заряд-зберігання-розряд» у кінетичних накопичувачах на розробленому прототипі групи кінетичних накопичувачів. У результаті проведених досліджень установлено що одиночне застосування накопичувача $є$ доцільним при режимі роботи, коли накопичувач розряджається приблизно на $60 \%$, після чого йде його заряд. При такому 
режимі маємо найбільший ККД. При груповому використанні кінетичних накопичувачів ефективність роботи при паралельному підключенні й одночасному режимі «заряд-розряд» досягається за необхідності швидкого покриття пікового навантаження. При почерговому алгоритмі роботи накопичувачів ефективність роботи досягається при довготривалому покритті навантаження. Зроблені висновки стосовно режимів роботи накопичувачів у системі «накопичувач-споживач» повністю підтверджуються отриманими навантажувальними діаграмами. Також експериментально отримані навантажувальні діаграми кінетичних накопичувачів при керуванні загальних параметрів, таких як частота обертання двигуна-генератора, часу заряду-розряду, величини накопиченої потужності й ККД, що дало змогу зробити висновки стосовно оптимальності їх вибору. Проведені дослідження мають практичну та наукову значимість. 3 наукового погляду маємо результати для подальшого дослідження кінетичних накопичувачів при оптимізації системи «накопичувач-споживач». Практична значимість полягає в застосуванні отриманих результатів під час проектування системи «накопичувач-споживач» для потреби електроенергетичних систем.

Ключові слова: навантажувальна діаграма, кінетичний накопичувач енергії (КНЕ), маховик, заряд-розряд накопичувача, алгоритм керування.

\section{References}

[1] Gulia, N.V. \& Katsay, A.V. Tsiklicheskiye ispytaniya nakopitelya kineticheskoy energii bol'shoy moshchnosti i energoyemkosti. URL: http://n-t.ru/tp/ts/ci.htm (access date 02.04.2020).

[2] Mosiyenko, A.B. (2004) Razrabotka algoritma i sistemy avtomaticheskogo upravleniya elektromekhanicheskogo nakopitelya dlya avtonomnykh energosistem [Development of an algorithm and automatic control system for an electromechanical drive for autonomous power systems] The dissertation for the degree candidate of technical sciences. Novosibirsk. 2004. 191 p [in Russian].

[3] Chang-Liang Tang* \& Xing-Jian Dai \& Xiao-Zhang Zhang \& Lei Jiang. (2012) Rotor dynamics analysis and experiment study of the flywheel spin test system. Journal of Mechanical Science and Technology. № 26 (9). $2669-2677$.

[4] Hitoshi Hasegawa, Hitoshi Matsue, Ken Nagashima, Tomohisa Yamashita. (2016) Flywheel Energy Storage System Using Superconducting Magnetic Bearings for Demonstration Tests. Quarterly Report of RTRI. № 57(3). $221-227$.

[5] Bubenchikov, A.A., Bubenchikova, T.V., Solov'yeva, Yu.O., Pogorelov, A.A., Gaibov, I.A., Monakova ,Ye.A. \& Zakharov A.A. Innovatsionnyye razrabotki vetroenergeticheskikh ustanovok. [Innovative development of wind power plants].URL:http://scipro.ru/conf/proceedings24012018.pdf\#page=86 [access date 09.04.2020].

[6] Dobrego, K.V. (2017) Model' elektricheskoy nagruzki zhilishchno-kommunal'nogo ob"yekta dlya issledovaniya sistem «generator - nakopitel' - potrebitel'» metodom Monte-Karlo[Monte Carlo Model of the electrical load of a housing and communal facility for the study of «generator - drive - consumer» systems]. Nauka i tekhnika. №16(2).160-170 [in Russian].

[7] Nadaraia, Ts.G., Babkina, L.A., Shestakov, I.Ya. \& Fadeyev, A.A. (2014) Khimiko-kineticheskiy nakopitel' energii [Chemical-kinetic energy storage]. Vestnik SibGAU. № 2(54). 56-61 [in Russian].

[8] Savchenko, N.P., Shevchenko, S.Yu. (2018) Matematicheskaya model' sistemy elektrosnabzheniya administrativnogo zdaniya s kineticheskim energonakopiteley [A mathematical model of the power supply system of an administrative building with kinetic energy storage]. Elektromekhanicheskiye i energosberegayushchiye sistemy. №1 (41). 47-52 [in Ukrainian].

Постановка проблеми. Високий інтерес до кінетичного накопичувача енергії (далі-КНЕ) зумовлений їх здатністю виконувати функції динамічного джерела живлення, рекуператора електроенергії й регулятора провалів електропостачання. Цикл роботи накопичувача «заряд-зберігання-розряд» визначається алгоритмом управління й технічними параметрами пристрою. Найбільш детально цей процес може бути продемонстрований за допомогою навантажувальної діаграми KНЕ, за характером якої можна судити про ефективність роботи одиночного накопичувача або групи накопичувачів залежно від різних факторів впливу. Для побудови навантажувальних діаграм досліджується залежність зміни величин енергії або потужності за певний проміжок часу. При цьому додатково зовнішній вигляд навантажувальної діаграми визначається впливом таких чинників, як частота обертання двигуна-генератора, вид управління й ККД. Отже, аналіз навантажувальних діаграм накопичувачів, отриманих при різних алгоритмах управління, дасть змогу визначити найбільш ефективний за енерговитратами цикл роботи накопичувача «заряд-зберігання-розряд» 3 оптимальними технічними характеристиками.

Аналіз останніх досліджень і публікацій. Останніми роками питання збереження енергії призвели до бурхливого розвитку технології накопичення енергії КНЕ в електроенергетичній галузі, а ось питання ефективності використання КНЕ в цільових умовах конкретних систем «накопичувач-споживач» висвітлені недостатньо й вимагають експериментального підтвердження. Основою для проведення дослідження роботи КНЕ при різних алгоритмах управління послугували наукові праці як вітчизняних, так і зарубіжних авторів $[1 ; 2 ; 3 ; 4 ; 5]$.

Також дуже важливим питанням для дослідження $є$ оптимізація системи «накопичувач-споживач», 
що дасть змогу вивести КНЕ на новий рівень порівняно з іншими типами накопичувачів за екологічністю, енергоефективністю й довговічністю.

Оптимізація системи «накопичувач-споживач» може включати, зокрема, використання гібридних систем накопичувачів спільно з різнорідними хімічними й механічними накопичувачами, 3 налаштуванням параметрів системи управління під певні алгоритми [6; 7].

Мета дослідження. Метою дослідження є перевірка ефективної працездатності одиночних і групових КНЕ при різних частотах обертання, дослідження енергоефективності роботи КНЕ при різних режимах роботи й алгоритмах управління.

Основний матеріал (результати). Навантажувальні діаграми роботи КНЕ є найбільш інформативними, коли розглядаються в функції часу. У загальному вигляді навантажувальна діаграма КНЕ представлена на рис. 1 [1;8].

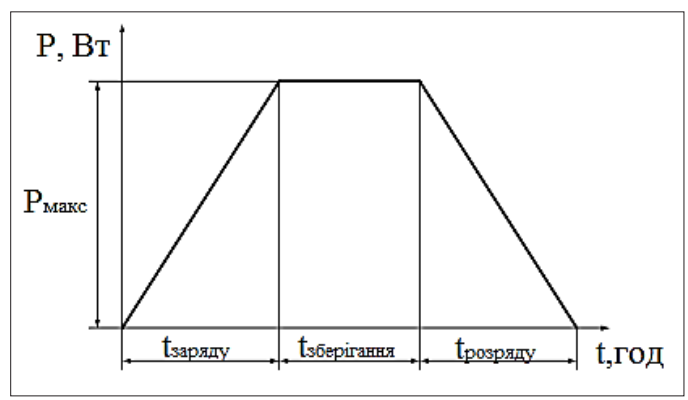

Рис. 1. Навантажувальна діаграма накопичувача

На діаграмі $t_{\text {заряду, }} t_{\text {зберігання }}, t_{\text {розряду }} \in$ змінними величинами часу й можуть регулюватися з метою отримання необхідного режиму роботи КЕН. Час заряду КЕН цілком залежить від потужності ЕМ і регулювання швидкості розгону ЕМ. Час розряду залежить від потужності підключеного навантаження [8].

Для перевірки працездатності й ефективності роботи поодинокого та групового КНЕ при різних алгоритмах керування зібрано прототип накопичувача, який представлений на рис. 2.

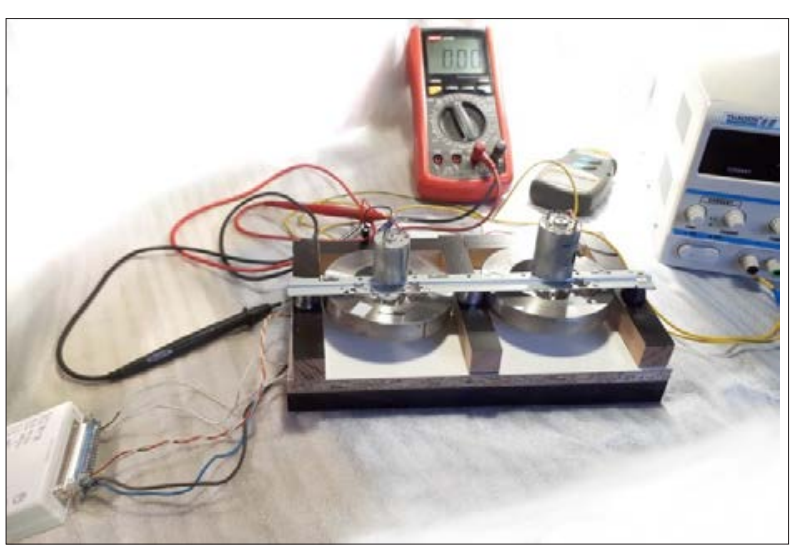

Рис. 2. Зовнішній вигляд експериментальної установки

Дослідження роботи одного КНЕ виконувалося за схемою, наведеною на рис. 3.

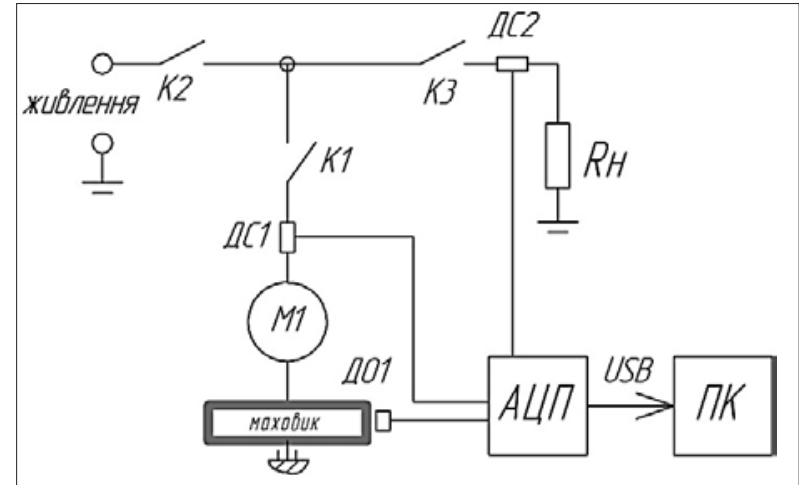

Рис. 3. Схема випробування з одним маховиком М - двигун постійного струму з постійними магнітами; К1, К2, К3 - ключі; ДС1, ДС2 - датчики струму (низькоомний шунт); Rн - навантаження (потужний змінний резистор); ДО1 - датчик обертів (датчик Холла); АЦП - аналогово-цифровий перетворювач (Е14-440); ПК - персональний комп’ютер.

Дослідження роботи одного КНЕ виконувалося 3 метою встановлення ефективного алгоритму керування та визначення оптимальних параметрів. Проведення експерименту й отримання навантажувальних діаграм виконано за такою послідовністю роботи прототипу: замикаються ключі К1 і К2, подається живлення через датчик струму ДС1 на двигун М. Як джерело живлення використовується лабораторний блок живлення з функцією обмеження струму в заданому діапазоні (Zhaoxin 305D). Двигун починає поступово розганяти маховик, значення струму та обертів фіксується через АЦП на ПК за допомогою П3 PowerGraph 3.3Pro.

Перед проведенням експерименту виконано тарування системи за допомогою амперметра й безконтактного оптичного тахометра. Відповідні коефіцієнти прописані в розділі налаштувань АЦП в ПЗ PowerGraph. Величина струму встановлена на рівні робочого струму мотора. При збільшенні обертів маховика струм поступово знижується приблизно до $10 \%$ від робочого. Цей показник є втрати у двигуні, підшипнику й тертя маховика об повітря. Після досягнення мінімального струму та максимальних обертів (накопичувач повністю заряджений) розмикається ключ К2 та замикається ключ К3, починається процес розряду накопичувача на навантаження. Виконавши декілька разів процес заряду, розряду, підрахували ККД накопичувача. Також визначено мінімальний рівень розряду накопичувача для його ефективного використання. Процес розряджання виконувався 3 максимально допустимим для мотора струмом, зі струмом 50\% та 20\% від максимального. Величину струму регулювали змінним резистором Rн. У результаті цього отримані такі графічні залежності (рис. 4).

На графіку потужність зі знаком «+»- це процес заряду накопичувача, потужність зі знаком «-»- процес розряду накопичувача.

3 графіків видно, що для заряду повністю розрядженого накопичувача потрібно більше енергії. 
Також видно, що оптимальним режимом роботи $€$ розряд накопичувача приблизно на $60 \%$ і потім повторний заряд. Судячи з експерименту, необхідна потужність для поповнення заряду в три рази менша, ніж при заряді повність розрядженого накопичувача.

Також обчислили ККД накопичувача, який становив $86 \%$, що вища, ніж у хімічних накопичувачів. Строк служби такого накопичувача значно більший за хімічний, тому не виникає проблем з екологічністю під час утилізації.
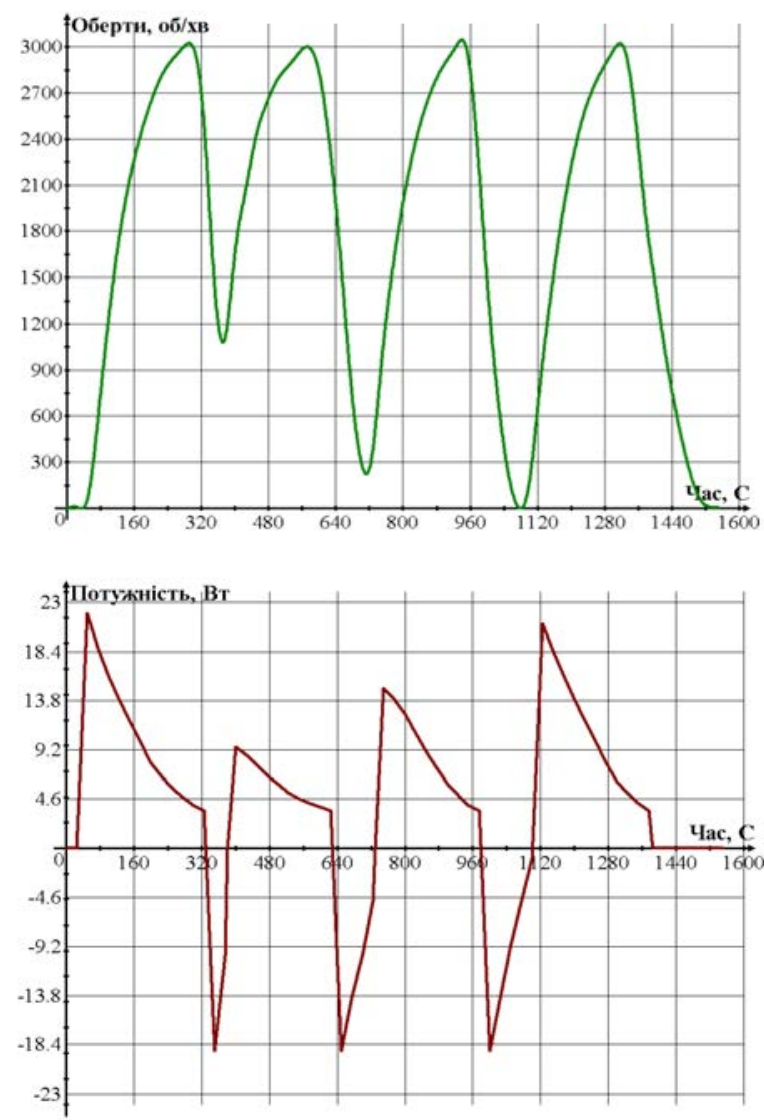

Рис. 4. Навантажувальні діаграми роботи одного накопичувача

Дослідження роботи групового КНЕ виконувалося за схемою, що наведена на рис. 5.

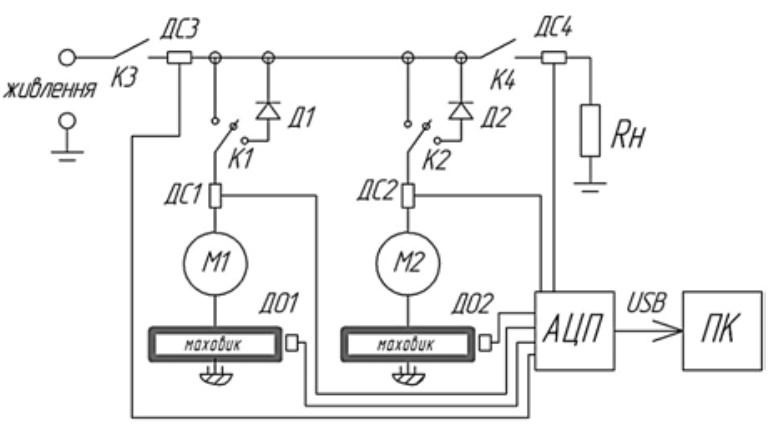

Рис. 5. Схема випробування 3 двома накопичувачами
Проведення експерименту й отримання навантажувальних діаграм виконано за такою послідовністю роботи прототипу: замикаються ключі К1, К2, К3, подається живлення через датчик струму ДС1, ДС2 на мотор M1, М2. Двигуни поступово розганяють маховики, реєструється струм та оберти. Після повного заряду накопичувачів розмикається ключ К3 й замикається ключ К4. Обидва накопичувача за заданим алгоритмом розряджаються на навантаження. Для уникнення взаємного впливу накопичувачів один на одного в схему добавлені діоди Д1 і Д2. Величина струму встановлена такою самою, як і в першому експерименті.

Алгоритми заряду-розряду:

Алгоритм 1. Обидва накопичувача одночасно заряджаються та розряджаються на навантаження.

Алгоритм 2. Зарядження одночасне, розрядження по черзі, один потім другий.

Алгоритм 3. Зарядження по черзі, розрядження по черзі.

Графічно процеси при першому алгоритмі управління накопичувачами представлені на рис. 6.
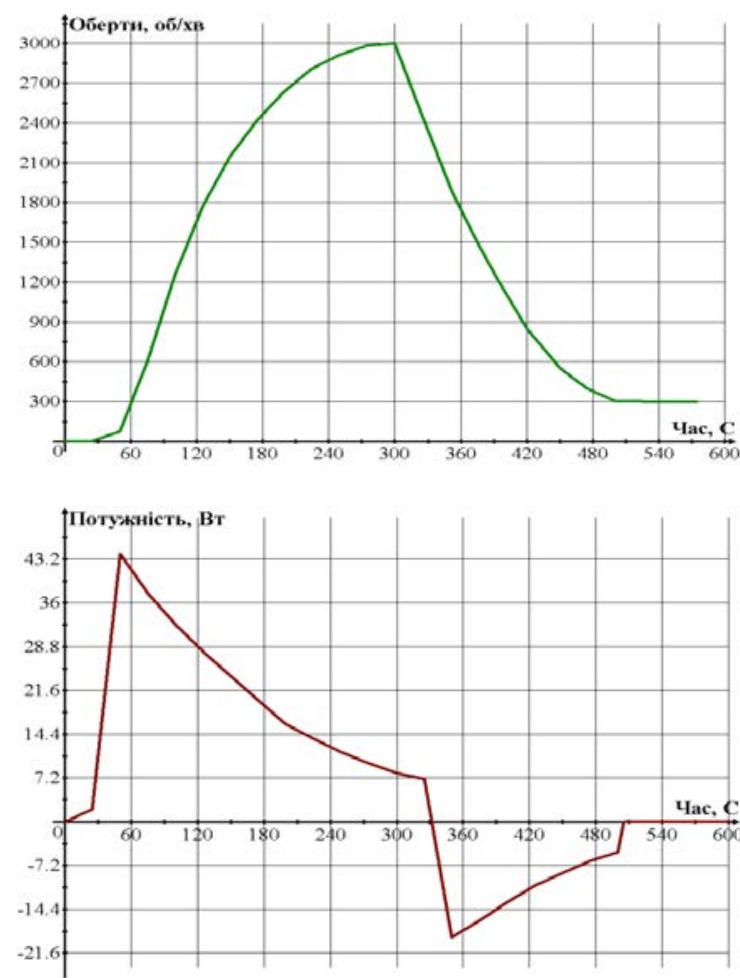

Рис. 6. Навантажувальні діаграми прототипу, коли обидва накопичувача одночасно заряджаються та розряджаються на навантаження

3 графіків видно, що потужність для заряду накопичувачів потрібна у два рази більша, але й час розряду також у два рази більший за умови величини навантаження, як і в першому випадку, для одного накопичувача. Вочевидь, такий спосіб варто використовувати, коли є досить велика потужність для заряду. 
Графічно процеси при другому алгоритмі управління накопичувачами представлені на рис. 7.
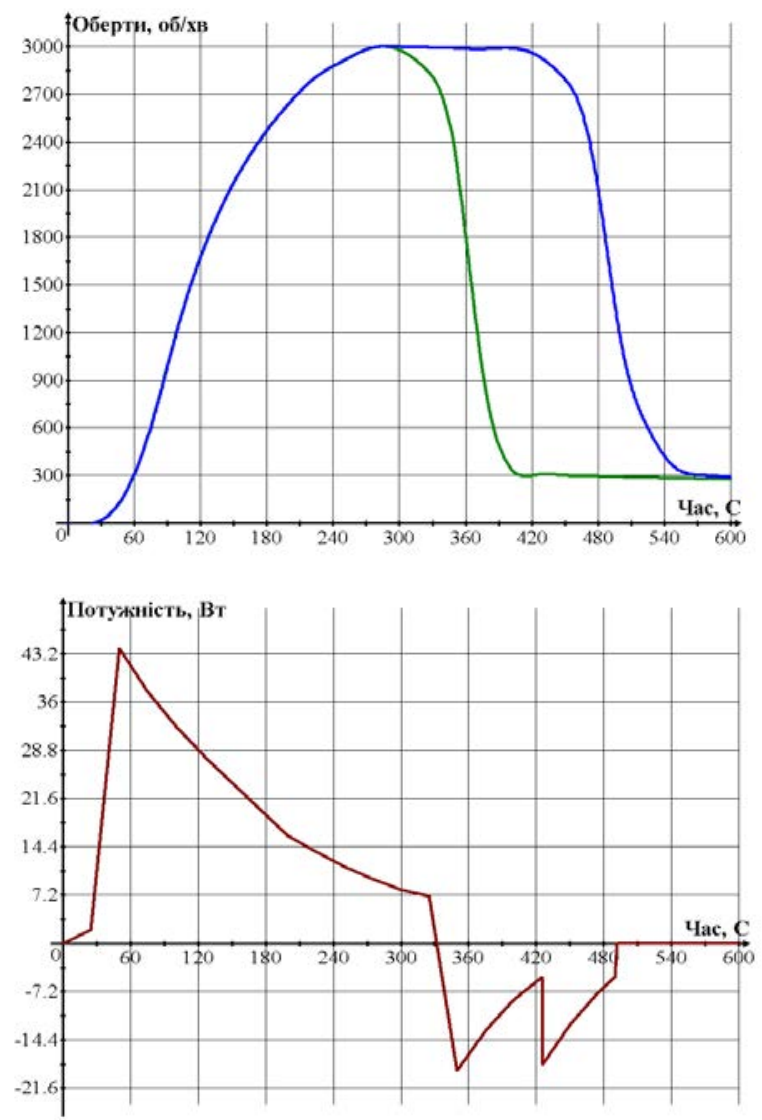

Рис. 7. Навантажувальні діаграми роботи прототипу, коли зарядження одночасне, розрядження по черзі, один, а потім другий

3 діаграм видно, що такий варіант роботи менш вигідний, необхідно виконувати перемикання накопичувачів під час роботи.

Графічно процеси при третьому алгоритмі управління накопичувачами представлені на рис. 8.

3 графіків видно, що такий режим найбільш підхожий для роботи 3 альтернативними джерелами енергії невеликої потужності. Якщо змістити в часі процес заряду та розряду, то цей варіант підходить для вирівнювання графіків навантаження електромережі.
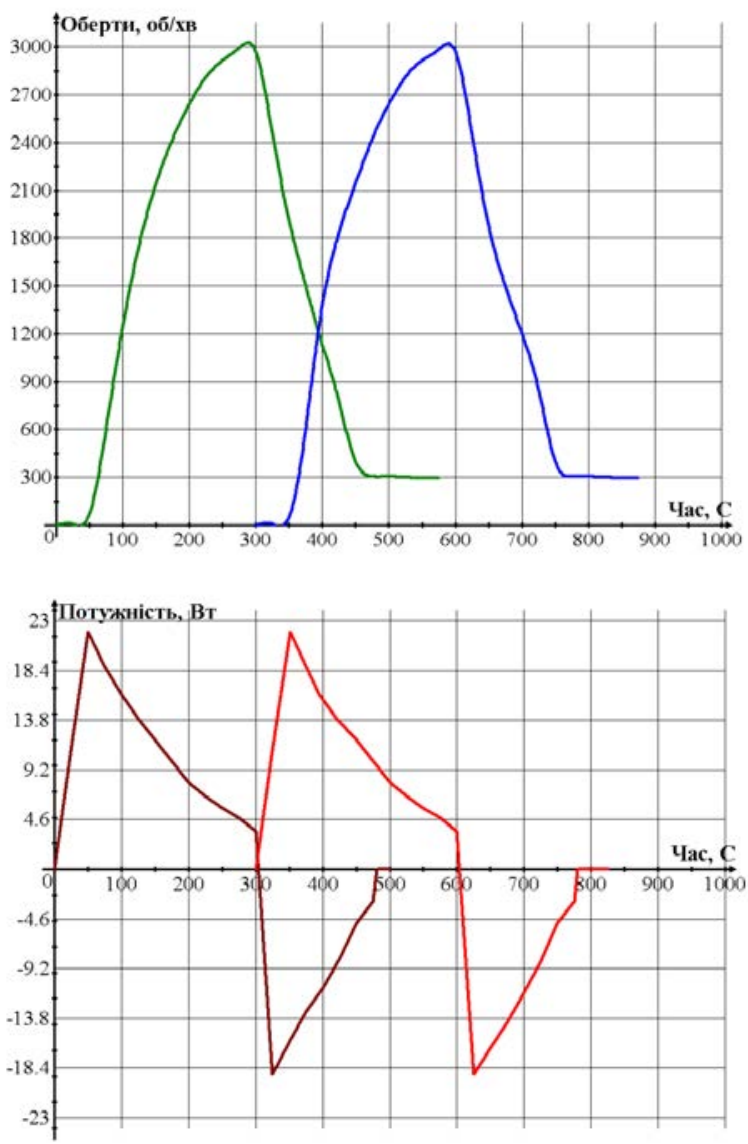

Рис. 8. Навантажувальні діаграми роботи прототипу, коли зарядження по черзі, розрядження по черзі

Висновки. У результаті експериментального дослідження режимів роботи кінетичних накопичувачів енергії в складі системи «накопичувач-споживач» отримані навантажувальні діаграми при різних алгоритмах керування процесом «зарядрозряд». Характер навантажувальних діаграм дає змогу пов'язати режими роботи накопичувачів та алгоритми керування зі спеціалізованими напрямами використання в електроенергетичних системах. Також за аналізом отриманих навантажувальних діаграм можна зробити висновки стосовно оптимальності вибору основних параметрів накопичувачів, таких як частота обертання двигуна-генератора, час заряду-розряду, величина накопиченої потужності й ККД.

\section{Список літератури:}

[1] Гулиа Н.В., Кацай А.В. Циклические испытания накопителя кинетической энергии большой мощности и энергоемкости. URL: http://n-t.ru/tp/ts/ci.htm (дата звернення: 02.04.2020).

[2] Мосиенко А.Б. Разработка алгоритма и системы автоматического управления электромеханического накопителя для автономных енергосистем : дисс. ... канд. тех. наук : 05.14.02. Новосибирск, 2004. 191 с.

[3] Chang-Liang Tang*, Xing-Jian Dai, Xiao-Zhang Zhang, Lei Jiang. Rotor dynamics analysis and experiment study of the flywheel spin test system. Journal of Mechanical Science and Technology. 2012. № 26 (9). P. 2669 -2677.

[4] Hitoshi Hasegawa, Hitoshi Matsue, Ken Nagashima, Tomohisa Yamashita. Flywheel Energy Storage System Using Superconducting Magnetic Bearings for Demonstration Tests. Quarterly Report of RTRI. 2016. № 57 (3). P. $221-227$.

[5] Инновационные разработки ветроэнергетических установок / А.А. Бубенчиков, Т.В. Бубенчикова, Ю.О. Соловьева, А.А. Погорелов, И.А. Гаибов, Е.А. Монакова, А.А. Захаров. URL: http://scipro.ru/conf/ proceedings24012018.pdf\#page=86 (дата звернення: 09.04.2020) 
[6] Добрего К.В. Модель электрической нагрузки жилищно-коммунального объекта для исследования систем «генератор - накопитель - потребитель» методом Монте-Карло*. Наука и техника. 2017. № 16 (2). С. $160-170$.

[7] Химико-кинетический накопитель энергии / Ц.Г. Надараиа, Л.А. Бабкина, И.Я. Шестаков, А.А. Фадеев. Вестник СибГАУ. 2014. № 2 (54). С. 56-61.

[8] Савченко Н.П., Шевченко С.Ю. Математична модель системи електропостачання адміністративної будівлі 3 кінетичним енергонакопичувачем. Електромеханічні і енергозберігаючі системи. 2018. № 1 (41). С. 47-52.

(C) Савченко Н. П., Трет'як А. В. Дата надходження статті до редакції: 29.04.2020 Дата затвердження статті до друку: 27.07.2020 